\title{
The Simulation of Weight-fixed Loading Hydraulic System with Skip Based on AMESim
}

\author{
YANE Fu-qiang ${ }^{1,}$, , Ren Zhong-quan ${ }^{2, b}$ and YUN Ge-e $e^{2, c}$ \\ ${ }^{1}$ School of Science, Xi'an University of Science \& Technology, Xi'an 710054, China \\ ${ }^{2}$ School of Mechanical Engineering, Xi'an University of Science \& Technology, Xi'an 710054, China \\ ayang_afreet@163.com, ${ }^{b}$ renzq@xust.edu.cn, ${ }^{\circ} 526516203 @ q q . c o m$
}

Keywords: Skip; Weight-fixed loading; Hydraulic; AMESim.

Abstract. The simulation model of the weight-fixed loading hydraulic system with skip at Wangshiwa Coal Mine was built to analyze the flow and pressure change of the system. According to the simulation results of one working cycle of hydraulic fix-weight loading, the lifting speed of hydraulic cylinder is smooth; the piston has a small descending displacement during the loading process, the relative error of system is less than $0.09 \%$. The fast descending of fully loaded skip could lead to a greater impact for the hydraulic cylinder, and it is suggested that the skip should be hoisted before hydraulic cylinder reposition. The fix position of pressure transmitter among the hydraulic cylinder and electromagnetic reversing valve has no effect on the measure results.

\section{Introduction}

Metering bucket loading system which is fixed capacity loading is widely used in most of the coal mines built before 1980s in China. The same volume of coal always have different weight according to different density, water content and other factors, thus the overload accidents are easier to occur. To avoid the overload accidents, the Coal Mine Safety Regulation revised stipulates that the skip hoisting must uses weight-fixed loading [1]. Many coal mines have developed weight-fixed loading system with different weighting principles and methods [2-8]. The weight-fixed loading hydraulic system built at Wangshiwa Coal Mine, Tongchuan City uses the hydraulic weighing principle, and the weight of coal loaded was obtained by detecting the pressure increment in the chambers of hydraulic cylinders which were fixed among the supporting cage beam at bottom of well. The application of the system improves the automation of the coal mine, but the hydraulic components and pipelines of the system often damage by the impulse caused during the loading process. The simulation of weight-fixed loading hydraulic system with skip was simulated based on AMESim to study the pressure and flow change during the loading process, and which could provide references for improving the system.

\section{Composition and working process of the weight-fixed loading hydraulic system}

As shown in Fig. 1, each weighing unit consists of two hydraulic cylinders which are fixed among the supporting cage beam at bottom of well, the pressure transmitter is connected to the bottom chambers of hydraulic cylinders to detect the pressure change. Another hydraulic cylinder is used to control the sluice open or close to control the coal loading. The electromagnetic reversing valves are used to control the up or down of the hydraulic cylinder. Other components of the system consist of motor, hydraulic pump, check valve, relief valve, pipelines, etc.

A working cycle of the loading process contains the lifting of hydraulic cylinder, loading, weighting and the fall of hydraulic cylinder.

(1) When the skip down to the hydraulic cylinder, the spool of electromagnetic reversing valve 2 moves right to connect the bottom chambers of hydraulic cylinders, the hydraulic oil flow to the bottom chambers thus the pistons rise until its displacement reach the setting value. 
(2) If the displacement of piston reaches the setting value, the spool of electromagnetic valve 2 reposition and starts to loading the coal until the pressure detected by the pressure transmitter 4 reaches the setting value according to the maximum lifting weight of skip.

(3) When the pressure reaches the setting value, another electromagnetic valve action to control the hydraulic cylinder close the coal flow into the skip. The spool of electromagnetic valve 2 moves left, and the hydraulic oil flow to the top chambers thus the pistons fall to its initial positon. Then the skip is hoisted by the winch, and the process above repeats to hoist coal from the bottom of well to the floor.

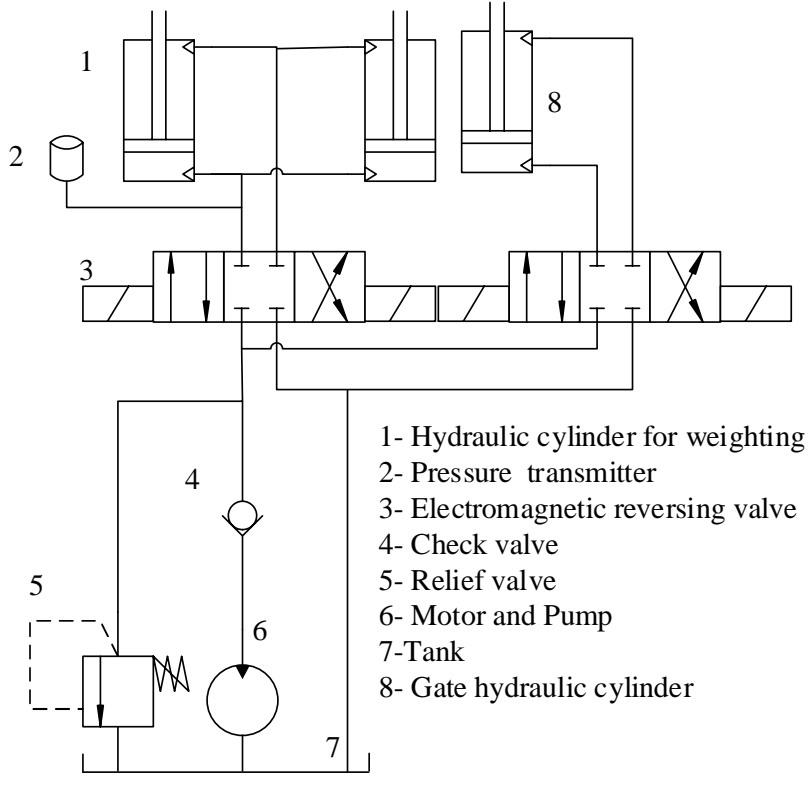

Fig. 1 The hydraulic schematic of weight-fixed loading hydraulic system
Table 1 Submodel of key components and parameters

\begin{tabular}{|c|c|c|}
\hline $\begin{array}{l}\text { Components } \\
\text { and Submodel }\end{array}$ & Parameters & Values \\
\hline \multirow{3}{*}{$\begin{array}{c}\text { Hydraulic } \\
\text { cylinder, HJ020 }\end{array}$} & Length of stroke [mm] & 2000 \\
\hline & Piston diameter [mm] & 150 \\
\hline & Rod diameter [mm] & 85 \\
\hline \multirow{2}{*}{$\begin{array}{c}\text { Check valve, } \\
\text { CV000 }\end{array}$} & Cracking pressure & 0.35 \\
\hline & $\begin{array}{c}\text { Flow rate pressure } \\
\text { gradient }[\mathrm{L} / \mathrm{min} / \mathrm{MPa}]\end{array}$ & 150 \\
\hline \multirow{2}{*}{$\begin{array}{l}\text { Relief valve, } \\
\text { RV001 }\end{array}$} & $\begin{array}{c}\text { Cracking pressure } \\
{[\mathrm{MPa}]}\end{array}$ & 15 \\
\hline & $\begin{array}{c}\text { Flow rate pressure } \\
\text { gradient }[\mathrm{L} / \mathrm{min} / \mathrm{MPa}]\end{array}$ & 325 \\
\hline \multirow{2}{*}{$\begin{array}{l}\text { Electromagnetic } \\
\text { reversing valve, } \\
\text { HSV34_1 }\end{array}$} & $\begin{array}{c}\text { Ports } \mathrm{P} \text { to } \mathrm{A}, \mathrm{B} \\
\text { pressure drop }[\mathrm{MPa}]\end{array}$ & 0.36 \\
\hline & $\begin{array}{c}\text { Ports } \mathrm{A}, \mathrm{B} \text { to } \mathrm{T} \\
\text { pressure drop }[\mathrm{MPa}]\end{array}$ & 0.30 \\
\hline
\end{tabular}

\section{Simulation model of the hydraulic weighing circuit}

The AMESim simulation model of the hydraulic weighing circuit is shown in Fig. 2, which is similar to the hydraulic schematic shown in Fig. 1. The differences are the logic control relationship is added, and the hydraulic cylinder to lift the skip is simplified to one according to the symmetry, thus the load applied on the hydraulic cylinder should be reduce to half when calculation. The model built can simulate one weighing circuit, concluding the lifting of hydraulic cylinder, loading, weighting and the fall of hydraulic cylinder.

The motor shaft speed is $1420 \mathrm{r} / \mathrm{min}$; the pump displacement is $25.36 \mathrm{ml} / \mathrm{r}$; the hydraulic oil has the density of $918 \mathrm{~kg} / \mathrm{m}^{3}$, absolute viscosity of $24.79 \mathrm{cP}$ and bulk modulus of $1.7 \times 10^{3} \mathrm{MPa}$; the pipelines connect the hydraulic cylinder and electromagnetic reversing valve have the length of $17 \mathrm{~m}$, inner diameter of $16 \mathrm{~mm}$ and wall thickness of $6 \mathrm{~mm}$. The other submodels of components and parameters are listed in Table 1.

\section{Results and discussion}

The simulation of weight-fixed loading process. The simulation was executed and continued for 20 s with sampling interval of $0.01 \mathrm{~s}$, the results are shown in Fig. 3. The spool of electromagnetic reversing valve located at middle with the control signal of $0 \mathrm{~mA}$. When the control signal changes to $-40 \mathrm{~mA}$, the port $\mathrm{P}$ connect to port $\mathrm{A}$, port $\mathrm{B}$ connect to port $\mathrm{T}$, and the pressure output rise a little when the hydraulic oil flow into the bottom chambers, the piston rises simultaneously. When the displacement of piston reaches $80 \mathrm{~mm}$, the control signal of electromagnetic reversing valve changes to $0 \mathrm{~mA}$ to reset the spool to the middle. Then the load was applied linearly, and the pressure detected also increases simultaneously. When the pressure reaches to setting value (equivalent to half the total 
weight of skip and coal loaded, $5.5 \times 10^{3} \mathrm{~kg}$ ), the control signal changes to $40 \mathrm{~mA}$ to connect the port A to $\mathrm{T}$ and $\mathrm{P}$ to $\mathrm{B}$, which induces the piston falling to its initial positon. During the one cycle, the piston rising lasts $2.4 \mathrm{~s}$, and the detected loading and the end is $48.37 \mathrm{kN}$, which equivalent to $4.94 \times 10^{3} \mathrm{~kg}$, during $9.88 \mathrm{~s}$; the hydraulic cylinder fall time is $0.65 \mathrm{~s}$.

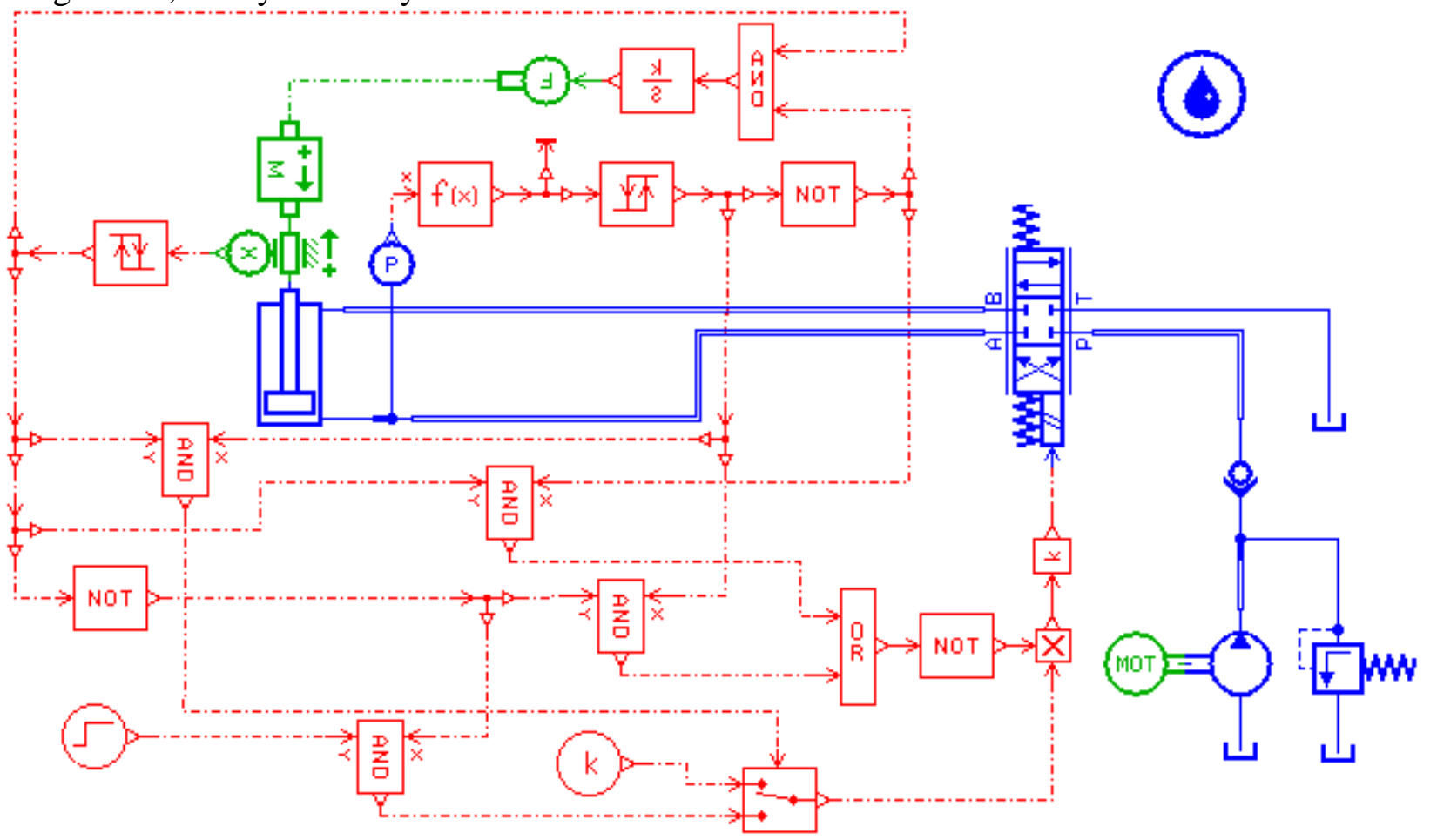

Fig. 2 AMESim simulation model of the hydraulic weighing circuit

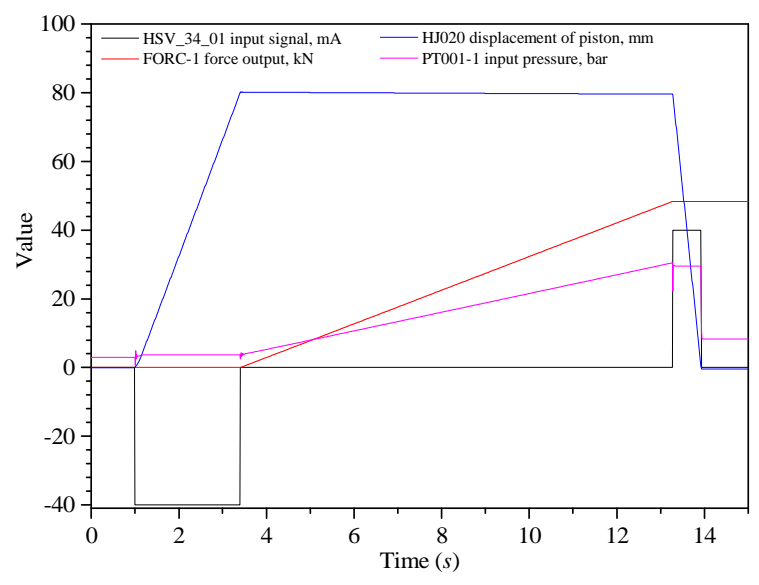

Fig.3 The simulation results of weight-fixed loading process

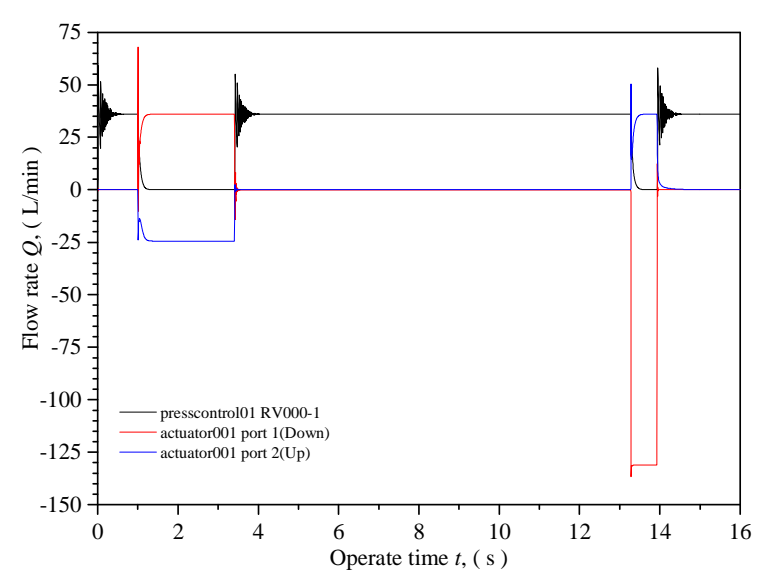

Fig.4 Flows during the weight-fixed loading process

Flows during the weight-fixed loading process. The flows in relief valve and the bottom and top chambers of hydraulic cylinder during the weight-fixed loading process are shown in Fig. 4. The stable initial flows of relief valve is $36 \mathrm{~L} / \mathrm{min}$, which equals to the flow of pump. When $t=1 \mathrm{~s}$, the electromagnetic reversing valve action, and the oil flows into the bottom chamber of hydraulic cylinder with $36 \mathrm{~L} / \mathrm{min}$, and flows out the top chamber of hydraulic cylinder with $24.44 \mathrm{~L} / \mathrm{min}$, the ratio is 1.47 and equals to the area ratio of rod cavity and rodless piston of the hydraulic cylinder. The calculated piston rise speed is $33.95 \mathrm{~mm} / \mathrm{s}$ based ton flow rates, the total rise time is $2.4 \mathrm{~s}$ and agrees with the simulation results. At the loading process, the flow rate at both chambers are 0 as the reversing valve is closed, the oil all flow into tank pass by the relief valve.

During the piston fall stage, the flow rate in bottom chamber is $130 \mathrm{~L} / \mathrm{min}$, while the top chamber is $36 \mathrm{~L} / \mathrm{min}$, the ratio is 3.6 and is bigger than the area ratio of rod cavity and rodless piston of the hydraulic cylinder. This indicates that the oil inflow to the top chamber cannot fill the cavity caused 
by piston fall. Thus the fall of piston is not caused by the pump but the skip and coal loaded themselves.

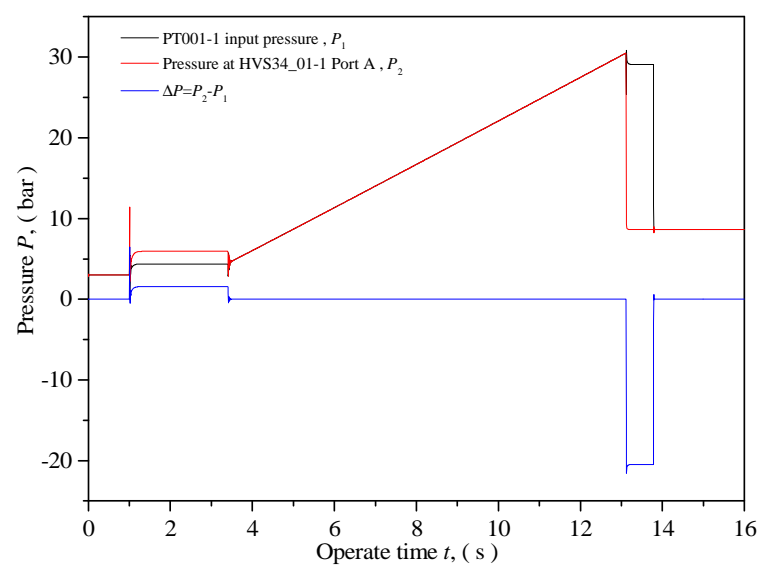

Fig. 5 Pressure changes in the pipe linked to the bottom chamber of the hydraulic cylinder during loading

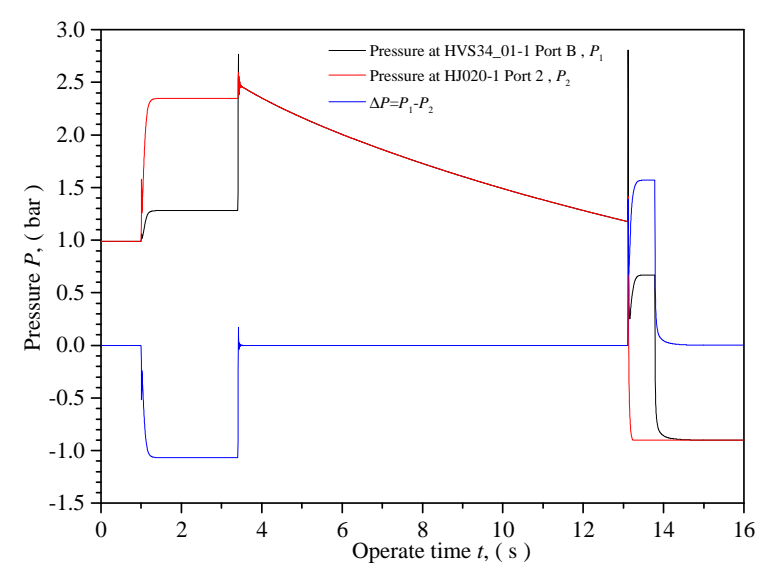

Fig. 6 Pressure changes in the pipe linked to the top chamber of the hydraulic cylinder during loading

Pressures change during the weight-fixed loading process. The flows in relief valve and the bottom and top chambers of hydraulic cylinder during the weight-fixed loading process are shown in It is the key issues to detect the pressure change accurately for the weight-fixed loading system. The pressure changes during the weight-fixed loading process in the pipe links the bottom chamber of the hydraulic cylinder and electromagnetic reversing valve in Fig. 5, it shows that initially the pressure is $0.3 \mathrm{MPa}$ and equivalent to $540 \mathrm{~kg}$, which is a little higher than the weight of skip. The pressure at both ends of the pipe is equal. At the rise stage, the pressures in pipe near the valve and near the bottom chamber of hydraulic cylinder are $0.594 \mathrm{MPa}$ and $0.437 \mathrm{MPa}$ respectively, the pressure differences is $0.157 \mathrm{MPa}$, this is the pressure loss of the flowing oil. At the loading stage, the pressure differences is less than $270 \mathrm{~Pa}$ and equivalent to $0.48 \mathrm{~kg}$. So it can be considered that the install location has no effect on the accuracy of system. The maximum pressure detected during the loading is $3.049 \mathrm{MPa}$, this value is equivalent to $5495.2 \mathrm{~kg}$, a little less than the actual load $5500 \mathrm{~kg}$, the relative error is less than $0.09 \%$. At the fall stage, the pressure near hydraulic cylinder is $2.91 \mathrm{MPa}$, the pressure near the valve is $0.862 \mathrm{MPa}$, the pressure loss in the pipe is $2.048 \mathrm{MPa}$.

Fig. 6 demonstrates the pressure changes in the pipe linked to the top chamber of the hydraulic cylinder during loading. It can be seen that the pressure loss at the raise stage is $0.107 \mathrm{MPa}$. At the loading stage, the pressure at the top chamber of hydraulic cylinder decreases with the increasing of applied load. This is because the oil is compressible and the pipe is inflatable, as the increasing of applied load, the volume of oil sealed in the bottom chamber of hydraulic cylinder and the pipe reduces, followed by the fall of piston and the volume increase of top chamber, thus the pressure of top chamber decreases with no inflow oil. At the fall stage, the top chamber forms a negative pressure of $-0.09 \mathrm{MPa}$, this is because the flow of pump cannot supply the cavity increment caused by the repaid fall of piston.

\section{Conclusions}

The working cycle of hydraulic fix-weight loading was simulated, and the results indicates that the lifting speed of hydraulic cylinder is smooth; the piston has a small descending displacement during the loading process, the relative error of system is less than $0.09 \%$. The pressure impulse caused by the status shift of valves is less than 1.5 times the working pressure and it is safety for hydraulic components. The hydraulic cylinder descending time is $0.65 \mathrm{~s}$ which leads to the piston fall with the speed of $120 \mathrm{~mm} / \mathrm{s}$, which could cause a momentum of $660 \mathrm{~kg} \cdot \mathrm{m} / \mathrm{s}$ with fully loaded skip, this will lead to a greater impact for the hydraulic cylinder. It is suggested that the skip should be hoisted before hydraulic cylinder reposition. The pressures at both ends of the pipe connecting the hydraulic cylinder and electromagnetic reversing valve is equal when applying the load, thus the fix position of pressure transmitter has no effect on the measure results. 


\section{Acknowledgements}

This work was supported by the National Natural Science Foundation of China (Grant No. 11502195), Natural Science Foundation of Shaanxi Provincial Department of Education (Grant No. 16JK1492) and Research Fund of Xi'an University of Science and Technology for Doctor (Grant No. 2016QDJ010).

\section{References}

[1] State Administration of Safety Supervision: Coal Mine Safety Regulation (China Coal Industry Publishing House, China 2016).

[2] J.J. Zhu: Coal Mine Machinery Vol. 33 No.3 (2012), p. 206.

[3] Z.F. Zhang, R. Guo and L.Y. Gui: Mine Construction Technology Vol. 36 No.1 (2015) p. 1.

[4] X.Lin and F.X. Meng: Industry and Mine Automation No.1 (2009) p. 120.

[5] Y.B. Lu, L. Wang, Y.Q. Chen, J.K. Yang and C.X. Song: Coal Mine Machinery No.5 (2005) p. 125.

[6] J.N. Zhu and P.H. Guo: China Safety Science Journal, Vol. 17 No. 7 (2007) p. 115.

[7] Y. Yu, X.J. Gong, R.C. Tian and Y. Zhang: Journal of Shandong University of Science and Technology (Natural Science) Vol. 23 No. 1 (2004) p. 61.

[8] X.F. Xu and Z.R. Zhou: Industry and Mine Automation No. 6 (2004) p. 32.

[9] L.J. Yao, C.X. Zheng, W. Bi and G.H. Ren: Industry and Mine Automation No. 2 (2012) p. 90. 